\title{
Autoinducer-2 regulates Pseudomonas aeruginosa PAO1 biofilm formation and virulence production in a dose-dependent manner
}

\author{
Hongdong $\mathrm{Li}^{1,2,3}$, Xingyuan $\mathrm{Li}^{4}$, Zhengli Wang ${ }^{1,2,3}$, Yakun $\mathrm{Fu}^{1,2,3}$, Qing $\mathrm{Ai}^{2,3}$, Ying Dong ${ }^{5}$ and Jialin $\mathrm{Yu}^{1,2,3^{*}}$
}

\begin{abstract}
Background: Pseudomonas aeruginosa is an opportunistic pathogen that is the leading cause of iatrogenic infections in critically ill patients, especially those undergoing mechanical ventilation. In this study, we investigated the effects of the universal signaling molecule autoinducer-2 (Al-2) in biofilm formation of $P$. aeruginosa PAO1.

Results: The addition of $0.1 \mathrm{nM}, 1 \mathrm{nM}$, and $10 \mathrm{nM}$ exogenous Al-2 to $P$. aeruginosa PAO1 increased biofilm formation, bacterial viability, and the production of virulence factors. However, compared to the $10 \mathrm{nM} \mathrm{Al-2}$ group, higher concentrations of Al-2 (100 nM and $1 \mu \mathrm{M}$ ) reduced biofilm formation, bacterial viability, and the production of virulence factors. Consistent with the changes in morphology, gene expression analysis revealed that Al-2 up-regulated the expression of quorum sensing-associated genes and genes encoding virulence factors at lower concentrations and down-regulated these genes at higher concentrations.

Conclusions: Our study demonstrated that exogenous Al-2 acted in a dose-dependent manner to regulate $P$. aeruginosa biofilm formation and virulence factors secretion via modulating the expression of quorum sensing-associated genes and may be targeted to treat $P$. aeruginosa biofilm infections.
\end{abstract}

Keywords: Autoinducer-2, Quorum sensing, Biofilm, Pseudomonas aeruginosa

\section{Background}

Pseudomonas aeruginosa is a well-known opportunistic pathogen associated with various acute and chronic infections in humans, especially in those who are immunocompromised. $P$. aeruginosa infections can be difficult to eradicate because $P$. aeruginosa is capable of forming biofilms, which are more resistant to physical or chemical attacks than planktonic bacteria, leading to high morbidity and mortality among infected patients [1,2]. P. aeruginosa could produce a number of virulence factors, such as pyocyanin, rhamnolipids, elastase, exotoxin A, phospholipase $\mathrm{C}$, and exoenzyme $\mathrm{S}$, which are thought to be involved in acute or chronic infections [3].

Quorum sensing (QS) is a cell-to-cell signaling system that refers to the ability of bacteria to respond to small

\footnotetext{
*Correspondence: yujialin468@163.com

'Department of Neonatology, Children's Hospital, Chongqing Medical

University, Chongqing, China

${ }^{2}$ Ministry of Education Key Laboratory of Child Development and Disorders,

Chongqing, China

Full list of author information is available at the end of the article
}

signaling molecules secreted by various microbial species. When the amount of QS signaling molecules accumulates to a threshold, the QS system is activated upon the identification of extracellular receptors. As typical QS signaling molecules, oligopeptides are often produced by Gram-positive bacteria, while N-acyl homoserine lactones are often produced by Gram-negative bacteria [4]. P. aeruginosa employs three interconnected QS systems, namely, las, rhl, and pqs, to control the expression of important virulence factors, and these factors play a crucial role in the development of biofilms [5]. Therefore, the QS system can be a suitable target for antimicrobial therapy. Numerous anti-infectious approaches against $P$. aeruginosa biofilms have been investigated during the past decade, such as antibiotic combinations [6] and some metal chelators exerting bactericidal and antibiofilm activities [7, 8]. However, the use of large numbers of antibiotics leads to a high prevalence of bacterial resistance, and the stability of metal chelators remains to be elucidated. Currently, chemical compounds that inhibit QS systems are being gradually investigated $[9,10]$. 
Autoinducer-2 (AI-2) is a universal QS molecule that mediates intra- and interspecies communication. This molecule is formed from spontaneous rearrangement of 4 , 5-dihydroxy-2, 3-pentanedione (DPD), which is produced by the enzyme LuxS, and is the primary QS molecule produced by many Gram-positive and Gram-negative bacteria. AI-2 has been shown to play a pivotal role in the life cycle of biofilms, including the initial bacterial aggregation and the production of virulence factors [11]. Previously, Duan et al. [12] and Roy et al. [13] found that AI-2 and AI-2 analogs had an impact on $P$. aeruginosa virulence, but the mechanism is not clear. Because $P$. aeruginosa is unable to produce AI-2 [12], the molecule might act as a parainducer, which can be sensed by the bacteria and thus affect its function. An example is reported in the study conducted by Geier et al., where AI-2 increased biofilm formation by Mycobacterium avium, which also cannot produce AI-2 [14].

In addition, we found high constituent ratios of Klebsiella spp. and Streptococcus spp. in the tracheal aspirates of ventilator-associated pneumonia (VAP) neonates [15], and P. aeruginosa is a common cause of VAP. Thus, we speculated that these AI-2 producers may facilitate biofilm formation by $P$. aeruginosa. In this study, we added different concentrations of synthetic $\mathrm{AI}-2$ to $P$. aeruginosa PAO1 and evaluated biofilm formation and the production of virulence factors, with an emphasis on the underlying mechanisms of AI-2 using transcriptional analysis.

\section{Methods}

\section{Bacterial strains and culture conditions}

$P$. aeruginosa wild-type PAO1 was kindly provided by Professor Li Shen (Institute of Molecular Cell and Biology, New Orleans, LA, USA). It was routinely grown and maintained on Luria-Bertani (LB) plates or in LB broth at $37{ }^{\circ} \mathrm{C}$ with agitation (200 rpm). Chemically synthesized AI-2 precursor DPD [(S)-4, 5-dihydroxy-2, 3-pentanedione] was purchased from Omm Scientific (Dallas, TX, USA).

\section{Growth assays}

Growth of PAO1 in the presence of $0.1 \mathrm{nM}, 1 \mathrm{nM}, 10$ $\mathrm{nM}, 100 \mathrm{nM}$, and $1 \mu \mathrm{M} \mathrm{AI}-2$ was measured at $600 \mathrm{~nm}$ at intervals of $2 \mathrm{~h}$ up to $24 \mathrm{~h}$ with a spectrophotometer (UV-1800, Shimadzu, Tokyo, Japan) [16]. All experiments were performed three times independently.

\section{Biofilm formation assay}

A static biofilm formation assay was performed in 96-well polystyrene microtiter plates as previously described with slight modifications [17]. In brief, cells from overnight cultures were standardized to an optical density at $600 \mathrm{~nm}$ (OD600) of 0.05. Two hundred microliters of the diluted cultures and various concentrations of AI-2 were added to 96-well microtiter plates (Costar, USA). After incubation for $24 \mathrm{~h}$ at $37{ }^{\circ} \mathrm{C}$ without agitation, the medium was discarded, and the plates were gently washed three times with $200 \mu \mathrm{L}$ phosphate-buffered saline (PBS). Then, the plates were air dried and stained with $0.1 \%$ crystal violet for $5 \mathrm{~min}$ at room temperature. Unattached stain was removed, and the plates were washed three times with PBS. The bacteria-bound crystal violet was dissolved in $200 \mu \mathrm{L}$ $95 \%$ ethanol, and the absorbance was determined at $570 \mathrm{~nm}$ in the microplate reader.

\section{Biofilm viability}

P. aeruginosa PAO1 cells were inoculated in LB broth at an initial OD600 of 0.05 and added to a sterile 24-well plate containing glass coverslips (Costar, USA) on which various concentrations of AI-2 were applied. Cultures were grown for $24 \mathrm{~h}$ without agitation at $37^{\circ} \mathrm{C}$. Coverslips were then rinsed three times with PBS and subsequently sonicated for $1 \mathrm{~min}$ (Tomy UD-201, Tokyo, Japan) and vortexed for $1 \mathrm{~min}$ at room temperature. Bacteria were harvested, enumerated by serial dilutions, and plated on LB agar. Plates were incubated at $37{ }^{\circ} \mathrm{C}$, and bacterial counts were determined after $24 \mathrm{~h}$.

\section{Confocal laser scanning microscopy}

$P$. aeruginosa PAO1 biofilms were established in 24-well plates as mentioned earlier. Cultures were grown for $48 \mathrm{~h}$ without agitation at $37{ }^{\circ} \mathrm{C}$. Coverslips were then washed and stained with SYTO9/propidium iodide according to the manufacturer's instructions of the L13152 LIVE/DEAD BacLight bacterial viability kit (Invitrogen Molecular Probes, USA). After staining for $15 \mathrm{~min}$ in the dark, biofilms were washed with sterile PBS to remove the planktonic dyes and bacteria, and then biofilms were visualized by excitation with an argon laser at $488 \mathrm{~nm}$ (emission: $515 \mathrm{~nm}$ ) and $543 \mathrm{~nm}$ (emission: $600 \mathrm{~nm}$ ) under a Nikon A1R laser confocal microscope (Nikon, Tokyo, Japan). Live bacteria were stained green while dead bacteria were stained red.

\section{Virulence factor assays}

For the pyocyanin assay, overnight cultures were standardized to an OD600 of 0.5 and diluted 1:10 in pyocyanin production broth (PPB; $2 \%$ proteose peptone [Oxoid, UK], $1 \% \mathrm{~K}_{2} \mathrm{SO}_{4}, 0.3 \% \mathrm{MgCl}_{2} \cdot 6 \mathrm{H}_{2} \mathrm{O}$ ) after growth in LB medium. A 5-mL sample of diluted culture with various concentrations of AI-2 was grown in $\mathrm{PPB}$ for $24 \mathrm{~h}$ and then extracted with $3 \mathrm{~mL}$ chloroform. The blue layer was re-extracted into $1 \mathrm{~mL} 0.2 \mathrm{M} \mathrm{HCl}$, yielding a red solution. The absorbance was measured at $520 \mathrm{~nm}$, and the pyocyanin concentration was determined by multiplying this measurement by 17.07 [18]. Elastase activity was measured using the elastin-Congo 
red (ECR) assay as previously described with moderate modifications [16]. Briefly, overnight cultures were standardized to an OD600 of 0.5 and diluted 1:10 in peptone tryptic soy broth (PTSB; $5 \%$ peptone, $0.1 \%$ tryptic soy broth) after growth in LB medium. A 5-mL sample of diluted cultures with and without various concentrations of AI-2 was grown in PTSB for $6 \mathrm{~h}$, and $100 \mu \mathrm{L}$ filtered supernatant was added to 5 - $\mathrm{mL}$ tubes containing $10 \mathrm{mg}$ of ECR (Sigma, USA), $900 \mu \mathrm{L} 10 \mathrm{mM}$ Tris $\mathrm{HCl}$ (pH 7.5), and $1 \mathrm{mM} \mathrm{CaCl}_{2}$. The tubes were incubated for $4 \mathrm{~h}$ at $37^{\circ} \mathrm{C}$ with shaking ( $250 \mathrm{rpm}$ ), followed by centrifugation to remove unreacted substrate. The absorbance at $495 \mathrm{~nm}$ was measured.

RNA extraction and quantitative real-time PCR (qRT-PCR) Overnight cultures of PAO1 at an initial OD600 of 0.05 were washed and then inoculated into fresh LB medium supplemented with various concentrations of AI-2 (0.1 $\mathrm{nM}$ to $1 \mu \mathrm{M})$ at an initial OD600 of 0.05 . Cultures were grown at $37^{\circ} \mathrm{C}$ with agitation for $24 \mathrm{~h}$. Total RNA was extracted and purified using the TaKaRa Minibest Universal RNA Extraction Kit (TaKaRa, Japan) according to the manufacturer's instructions. The concentration and purity of extracted total RNA was determined by ultraviolet absorption (260/280 nm) using a NanoDrop ND-1000 spectrophotometer (NanoDrop Technologies, Wilmington, DE, USA). The first-strand cDNA was generated from a purified mRNA sample using a PrimeScript RT reagent Kit with gDNA Eraser (TaKaRa). Real-time PCR was carried out using the SsoFast Evagreen Supermix Kit (BioRad, CA, USA) with a Bio-Rad Real-Time PCR instrument. The reaction procedure was performed as follows: $95{ }^{\circ} \mathrm{C}$ for $30 \mathrm{~s}, 40$ cycles of $95^{\circ} \mathrm{C}$ for $5 \mathrm{~s}$, and $60{ }^{\circ} \mathrm{C}$ for $5 \mathrm{~s}$, and a final melting curve analysis from $65{ }^{\circ} \mathrm{C}$ to $95^{\circ} \mathrm{C}$, with increments of $0.5^{\circ} \mathrm{C}$ every $5 \mathrm{~s}$. Real-time PCR amplifications were conducted in triplicate.

Primer sequences for $P$. aeruginosa QS genes and virulence genes were used as described previously (Table 1). The ribosomal gene rpsL was chosen as a housekeeping gene to normalize the qRT-PCR data and to calculate the relative fold changes in gene expression. Amplification profiles were analyzed using Bio-Rad Manager Software, and cycle threshold $(\mathrm{Ct})$ values for each target gene were normalized to the geometric mean of the Ct of rpsL amplified from the corresponding sample. The fold change of target genes for each group with respect to the control group was calculated using the $\Delta \Delta C$ t method.

\section{Statistical analysis}

Continuous data from this study were expressed as means \pm standard deviation. Independent unpaired data were analyzed using the Student's $t$-test. One-way analysis of variance was used for multi-group comparisons. Statistical analyses were performed using SPSS version 17.0 (SPSS, Inc., Chicago, IL, USA). $P<0.05$ was considered to be statistically significant.

Table 1 PCR primers for real-time RT-PCR

\begin{tabular}{|c|c|c|c|}
\hline Gene & Primer direction & Sequence $\left(5^{\prime}-3^{\prime}\right)$ & Amplicon size (bp) \\
\hline \multirow[t]{2}{*}{ lasl } & Forward & GGCTGGGACGTTAGTGTCAT & 104 \\
\hline & Reverse & AAAACCTGGGCTTCAGGAGT & \\
\hline \multirow[t]{2}{*}{ lasR } & Forward & ACGCTCAAGTGGAAAATTGG & 111 \\
\hline & Reverse & TCGTAGTCCTGGCTGTCCTT & \\
\hline \multirow[t]{2}{*}{$r h l l$} & Forward & AAGGACGTCTTCGCCTACCT & 130 \\
\hline & Reverse & GCAGGCTGGACCAGAATATC & \\
\hline \multirow[t]{2}{*}{$r h / R$} & Forward & CATCCGATGCTGATGTCCAACC & 101 \\
\hline & Reverse & ATGATGGCGATTTCCCCGGAAC & \\
\hline \multirow[t]{2}{*}{ las $A$} & Forward & GCGCGACAAGAGCGAATAC & 94 \\
\hline & Reverse & CGGCCCGGATTGCAT & \\
\hline \multirow[t]{2}{*}{ las $B$} & Forward & AGACCGAGAATGACAAAGTGGAA & 81 \\
\hline & Reverse & GGTAGGAGACGTTGTAGACCAGTTG & \\
\hline \multirow[t]{2}{*}{ phzH } & Forward & TGCGCGAGT TCAGCCACCTG & 214 \\
\hline & Reverse & TCCGGGACATAGTCGGCGCA & \\
\hline \multirow[t]{2}{*}{$r h / A$} & Forward & TGGCCGAACATTTCAACGT & 107 \\
\hline & Reverse & GATTTCCACCTCGTCGTCCTT & \\
\hline \multirow[t]{2}{*}{ rpsL } & Forward & GCAACTATCAACCAGCTGGTG & 231 \\
\hline & Reverse & GCTGTGCTCTTGCAGGTTGTG & \\
\hline
\end{tabular}




\section{Results}

\section{Effects of Al-2 on $P$. aeruginosa growth}

To test the impact of AI-2 on $P$. aeruginosa biofilm formation and virulence, we first investigated its effect on planktonic bacterial growth. The $1-\mu \mathrm{M}$ concentration of AI-2 did not influence the growth of the planktonic cultures (Fig. 1).

\section{Effects of $\mathrm{Al}-2$ on biofilm formation}

A dose-dependent effect of AI-2 on the biofilm formation of $P$. aeruginosa PAO1 was observed as demonstrated in Fig. 2. Biofilm formation increased in the presence of $0.1 \mathrm{nM}, 1 \mathrm{nM}$, and $10 \mathrm{nM}$ AI-2 with a 1.1-, 1.3-, and 1.4-fold increase in biofilm biomass compared to the negative control. It should be noted that $10 \mathrm{nM}$ AI-2 had the greatest impact on $P$. aeruginosa PAO1 biofilm formation $(P<0.05)$. However, higher concentrations (100 nM and $1 \mu \mathrm{M}$ AI-2) resulted in a lower biofilm biomass increase than $10 \mathrm{nM}$ AI-2.

Consistent findings were also demonstrated by confocal laser scanning microscopy. Increased AI-2 concentrations led to increased biofilm formation and the promotion of the three-dimensional structure of the biofilm (Fig. 3). A dense and compact biofilm was observed in the $10 \mathrm{nM}$ AI-2 group, and the number of viable bacteria in the control was less than that in the $1 \mathrm{nM}$ and 10 nM AI-2 groups. Furthermore, the biofilm thickness in the $1 \mathrm{nM}$ and $10 \mathrm{nM}$ AI-2 groups was significantly increased compared with that in the control group (Fig. 4).

\section{Biofilm viability}

The mean number of bacteria recovered from the biofilms (Fig. 5) in the $1 \mathrm{nM} \mathrm{AI-2}$ group $\left(2.16 \times 10^{8} \mathrm{cfu} / \mathrm{cm}^{2}\right), 10$ nM AI-2 group $\left(2.64 \times 10^{8} \mathrm{cfu} / \mathrm{cm}^{2}\right)$, and $100 \mathrm{nM} \mathrm{AI-2}$ group $\left(2.05 \times 10^{8} \mathrm{cfu} / \mathrm{cm}^{2}\right)$ was significantly greater than that in the control group $\left(1.62 \times 10^{8} \mathrm{cfu} / \mathrm{cm}^{2}\right)(P<0.05)$. However, the mean number of bacteria in the $0.1 \mathrm{nM}$ AI-2

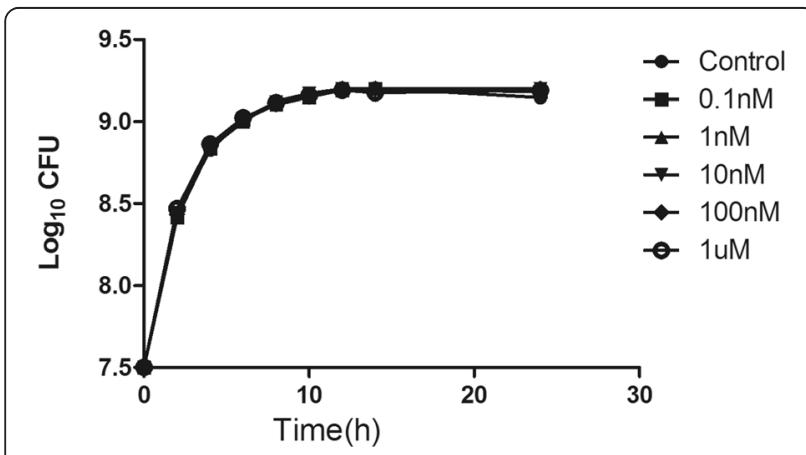

Fig. 1 Effects of Al-2 on planktonic growth of $P$. aeruginosa PAO1. Cells were grown in LB medium, in the presence of different concentrations of $\mathrm{Al}-2(0.1 \mathrm{nM}, 1 \mathrm{nM}, 10 \mathrm{nM}, 100 \mathrm{nM}$ and $1 \mu \mathrm{M})$. The data represent mean values of three independent experiments. Error bars represent the standard errors of the means

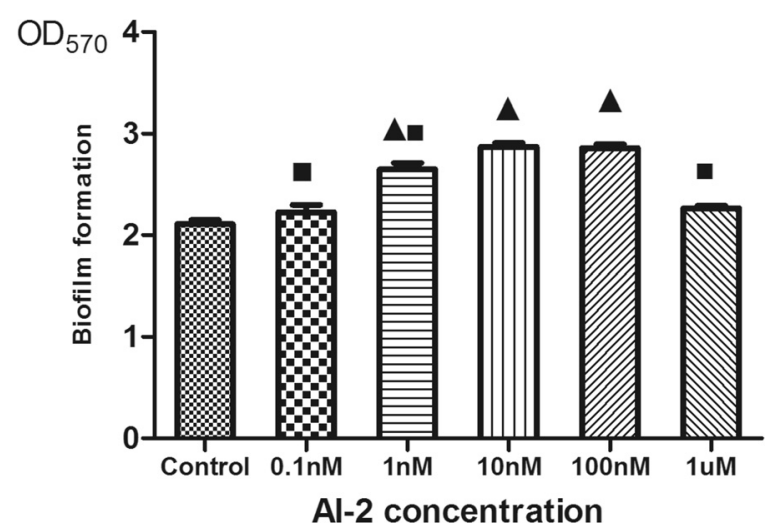

Fig. 2 Effects of Al-2 on P. aeruginosa PAO1 biofilm formation. Biofilm formation was assessed by crystal violet after static incubation at $37^{\circ} \mathrm{C}$ for $24 \mathrm{~h}$. Error bars represent SEM and all experiments were performed in triplicate with three independent assays; Triangles denote a statistically significant difference from the control $(P<0.05)$. Squares denote a statistically significant difference from the 10nM Al-2 group $(P<0.05)$

group $\left(1.8 \times 10^{8} \mathrm{cfu} / \mathrm{cm}^{2}\right)$ and the $1 \mu \mathrm{M}$ AI-2 group $\left(1.66 \times 10^{8} \mathrm{cfu} / \mathrm{cm}^{2}\right)$ was slightly greater than that in the control group, but the increase was not significant $(P>0.05)$. These results were consistent with biofilm morphology changes and suggest that AI-2 increases the viability of $P$. aeruginosa PAO1 biofilms.

\section{Induction of virulence factor production}

To study the impact of AI-2 on P. aeruginosa virulence, two important factors, namely pyocyanin and elastase, which are controlled by QS were measured [19]. The activity of both pyocyanin and elastase in PAO1 were increased by AI-2 in a dose-dependent manner (Fig. 6a and $b)$. A significant increase $(P<0.05)$ in pyocyanin and elastase production was observed in the presence of 1 $\mathrm{nM}$ and $10 \mathrm{nM}$ AI-2.

\section{Gene expression analysis with qRT-PCR}

QS is the most important regulator of biofilm formation by $P$. aeruginosa. To investigate whether the effect of AI-2 on the virulence of $P$. aeruginosa was the result of interference with QS, qRT-PCR was used to monitor the expression of QS-associated genes. The mRNA level of QS genes and virulence genes of $P$. aeruginosa biofilms, including rhlI, rhlR, lasI, lasR (QS-associated genes), las $A$ (encoding protease), las $B$ (encoding elastase), $p h z H$ (encoding pyocyanin), and $r h l A$ (encoding rhamnosyltransferase), increased with increasing AI-2 concentrations (from 0 to $10 \mathrm{nM}$ ) and decreased with $100 \mathrm{nM}$ and $1 \mu \mathrm{M}$ AI-2 (Table 2), which was consistent with the morphology changes. Especially, with $10 \mathrm{nM}$ AI-2, the expression of lasI, lasR, rhlI, rhlR, las A, las $B, p h z H$, and rhlA was increased by 2.3-, 1.1-, 1.3-, 2.5-, 10-, 11-, 9.5-, 

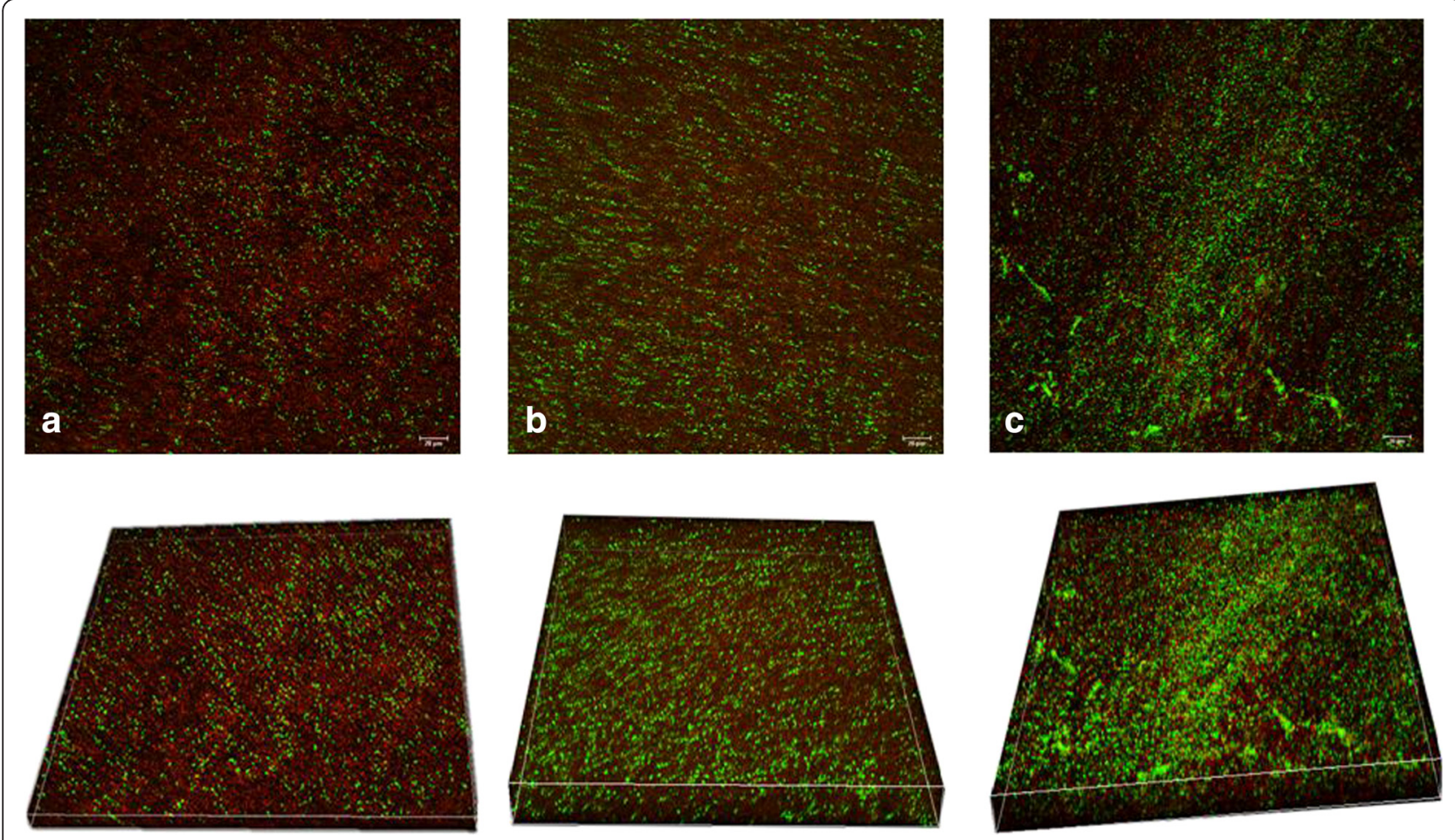

Fig. 3 Confocal laser scanning micrographs of 2-day P. aeruginosa PAO1 biofilms treated under different concentrations of Al-2 ( $\times 400)$. Bacterial viability was determined using L13152 LIVE/DEAD BacLight bacterial viability kit. a No exposure to Al-2; b Exposure to $1 \mathrm{nM}$ Al-2; $\mathbf{c}$ Exposure to 10nM Al-2. Cells staining red are considered dead while cells staining green are viable cells. The scale bar represents $20 \mu \mathrm{m}$

and 3.7-fold, respectively; these increases were statistically significant when normalized to a control gene $(P<$ $0.05)$. These results indicated that exogenous AI-2 could up-regulate the expression of QS-associated genes of $P$. aeruginosa PAO1.

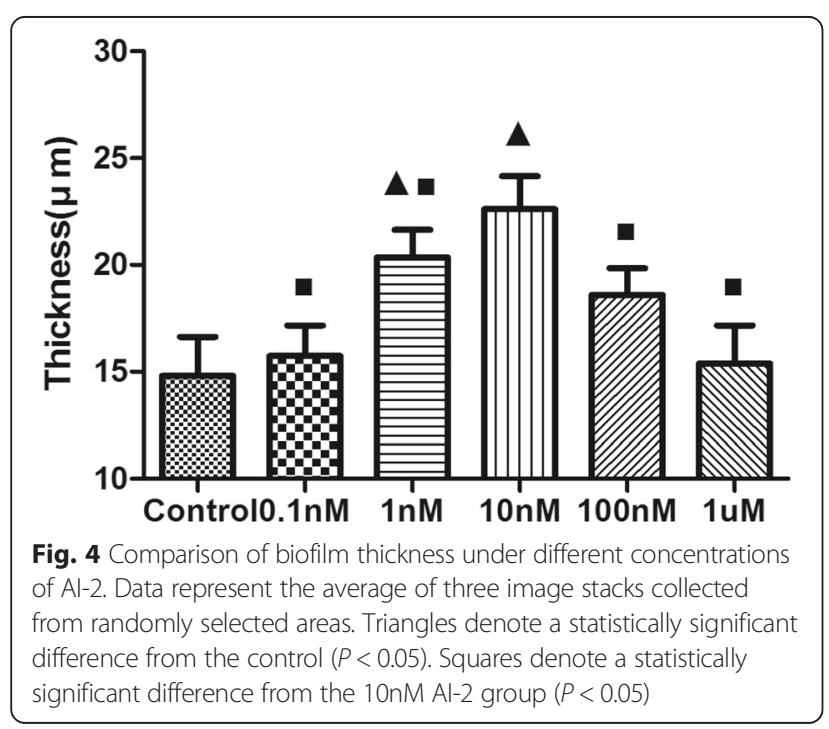

\section{Discussion}

$P$. aeruginosa is a prevalent environmental bacterium that is responsible for various recalcitrant infections in humans. It is also one of the most prevalent isolates in sputum samples of neonates with VAP [20]. In this

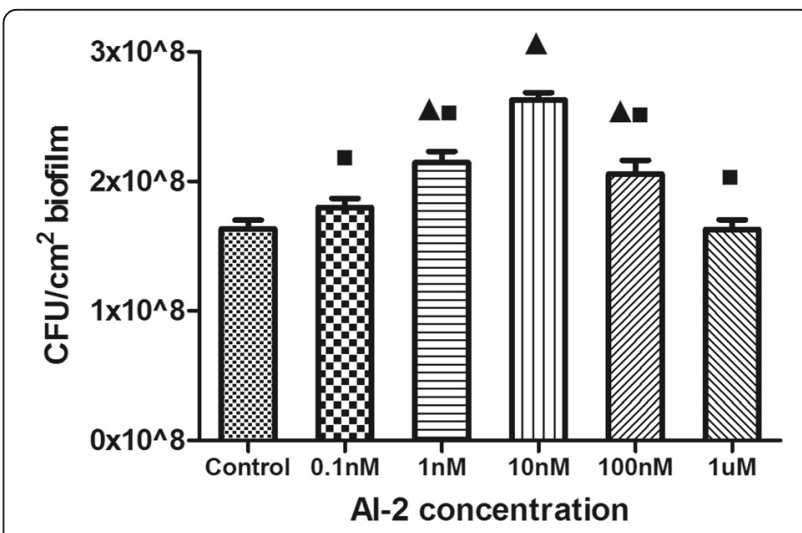

Fig. 5 Enumeration of viable bacteria under different concentrations of Al-2. Data represent the means and standard deviations of three independent experiments. Triangles denote a statistically significant difference from the control $(P<0.05)$. Squares denote a statistically significant difference from the $10 \mathrm{nM} \mathrm{Al-2}$ group $(P<0.05)$ 


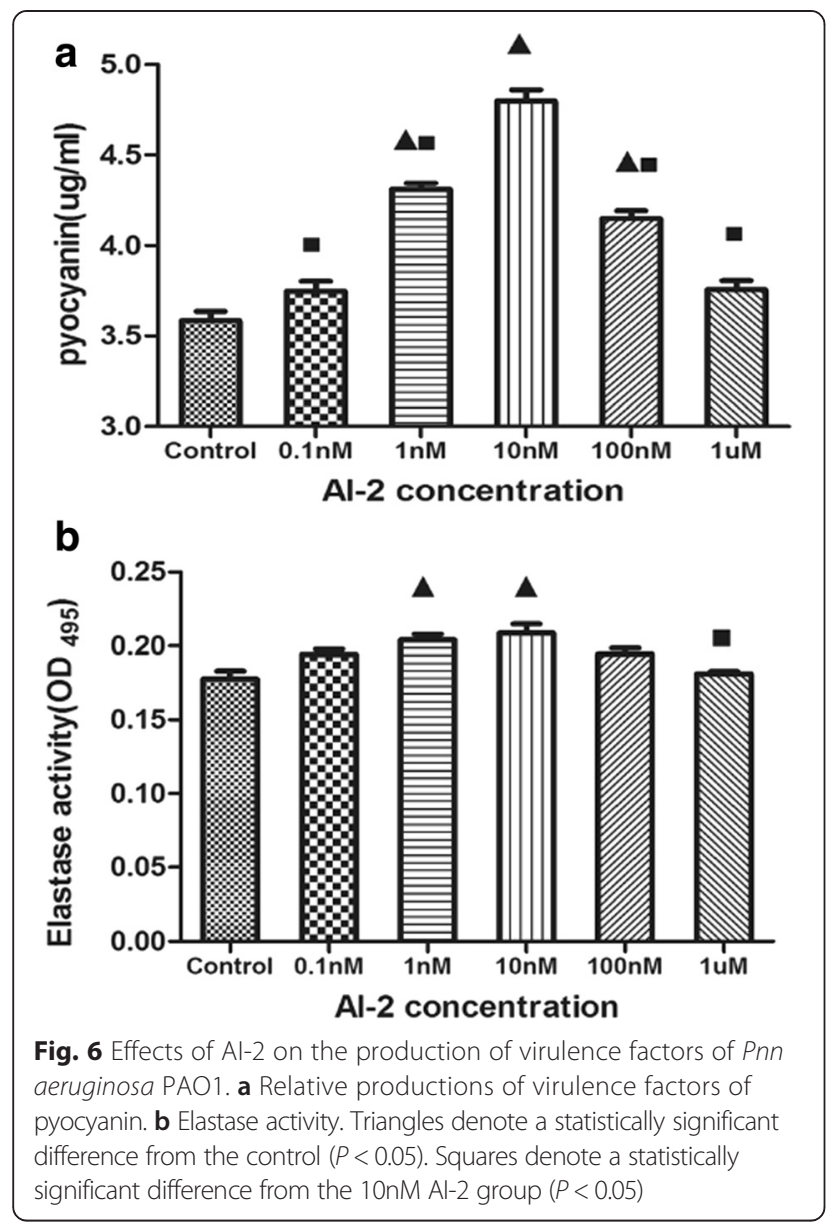

study, we demonstrated that AI-2 induced virulence factor production, biofilm biomass, and bacterial viability of $P$. aeruginosa PAO1 in a dose-dependent manner, and AI-2 did not impact its planktonic growth. Furthermore, AI-2 influenced the expression of QS-associated genes

Table 2 QS and virulence genes regulated by Al-2 of $P$. aeruginosa biofilm

\begin{tabular}{|c|c|c|c|c|c|c|}
\hline \multirow[t]{2}{*}{ Gene } & \multicolumn{6}{|c|}{ Fold change in expression } \\
\hline & 0 & $0.1 \mathrm{nM}$ & $1 \mathrm{nM}$ & $10 \mathrm{nM}$ & $100 \mathrm{nM}$ & $1 \mu \mathrm{M}$ \\
\hline |asl & 1 & $1.9 \pm 0.1$ & $2.7 \pm 0.2^{*}$ & $3.3 \pm 0.2^{*}$ & $2.2 \pm 0.18^{*}$ & $2 \pm 0.2^{*}$ \\
\hline lasR & 1 & $1.3 \pm 0.1$ & $1.9 \pm 0.16$ & $2.1 \pm 0.23^{*}$ & $1.3 \pm 0.16$ & $1.3 \pm 0.2$ \\
\hline$r h l l$ & 1 & $1.5 \pm 0.17$ & $2.1 \pm 0.1^{*}$ & $2.3 \pm 0.13^{*}$ & $1.7 \pm 0.16$ & $1.2 \pm 0.1$ \\
\hline$r h / R$ & 1 & $2.1 \pm 0.2^{*}$ & $3.4 \pm 0.3^{*}$ & $3.5 \pm 0.24^{*}$ & $2.2 \pm 0.13^{*}$ & $1.8 \pm 0.3$ \\
\hline las $A$ & 1 & $4.3 \pm 0.16^{*}$ & $5.1 \pm 0.27^{*}$ & $11 \pm 0.21^{*}$ & $4 \pm 0.21^{*}$ & $3 \pm 0.18^{*}$ \\
\hline$l a s B$ & 1 & $4 \pm 0.14^{*}$ & $5.8 \pm 0.45^{*}$ & $12.7 \pm 1.7^{*}$ & $5 \pm 0.15^{*}$ & $2.8 \pm 0.13^{*}$ \\
\hline phzH & 1 & $3.6 \pm 0.34^{*}$ & $5.8 \pm 0.67^{*}$ & $10.6 \pm 0.7^{*}$ & $3.8 \pm 0.16^{*}$ & $3.3 \pm 0.22^{*}$ \\
\hline$r h / A$ & 1 & $2.2 \pm 0.16^{*}$ & $3.7 \pm 0.33^{*}$ & $4.8 \pm 0.56^{*}$ & $2.3 \pm 0.14^{*}$ & $2.1+0.14^{*}$ \\
\hline
\end{tabular}

Values marked with an asterisk $\left(^{*}\right)$ indicate that the fold change of relative gene expression level of $P$. aeruginosa PAO1 in the presence of different concentrations of $\mathrm{Al}-2$ was significantly different from negative control at $P<0.05$ (e.g., lasI, lasR, rhlI, and rhlR). This indicated that AI-2 affected the virulence of $P$. aeruginosa by inducing the activity of the QS systems.

Although the role of AI- 2 as a general bacterial signaling molecule is yet to be completely unraveled, AI-2 is known to be involved in biofilm formation. AI-2 inhibits biofilm formation in Bacillus cereus [21], Candida albicans [22], and Eikenella corrodens [23], and it promotes biofilm formation in Escherichia coli [24], Streptococcus mutans [25], and multispecies biofilms between the two oral bacteria Streptococcus gordonii and Porphyromonas gingivalis [26]. The addition of exogenous AI-2 to P. aeruginosa biofilms increased biofilm formation, indicating that $P$. aeruginosa responds to the molecule. This study revealed that AI-2 can be a parainducer as a QS molecule regulating $P$. aeruginosa biofilms.

A similar concentration-dependent effect of AI-2 on biofilm formation has been reported for Streptococcus suis [27], Bacillus cereus [21], Streptococcus oralis [28], and Mycobacterium avium [14]. A previous study by Duan et al. [12] demonstrated that AI-2 was detected in sputum samples from patients with cystic fibrosis, and AI-2 regulated gene expression patterns and pathogenesis of $P$. aeruginosa. However, the mechanism is not known. In addition, Duan et al. found that the important virulence genes las $A$ and exotoxin genes exoS and exo $Y$ were not regulated by AI-2. This phenomenon may be attributed to the too high or too low concentration of AI-2 because our results showed that the las $A$ gene was affected by AI-2. Furthermore, we found that in vitro co-culture of the AI-2 producer Streptococcus mitis and P. aeruginosa PAO1 promoted $P$. aeruginosa PAO1 biofilm formation at certain concentrations (data not shown). It also has been suggested that the LuxS enzyme regulates metabolic processes in a large range of bacteria [29, 30]. In the present study, we found that AI-2 regulated the metabolic rate of cells in $P$. aeruginosa PAO1 biofilms. First, more viable cells were observed in the AI-2 group by confocal laser scanning microscopy, and plating experiments revealed that the bacterial reproduction of the AI- 2 group is faster than that of the control group. Second, the rhl QS system is a metabolic regulator for $P$. aeruginosa [31]. In this study, the increased expression levels of the rhlI and $r h l R$ genes, which are related to bacterial metabolism, may lead to increased biofilm formation and metabolic rate as the concentration of AI-2 increased.

AI-2 is a cell-signaling regulator of $P$. aeruginosa. It contributes substantially to the biofilm formation of $P$. aeruginosa and plays an important role in the pathogenesis of $P$. aeruginosa infections. This phenomenon may be due to the up-regulation of QS genes and virulence factor genes such as las $B$, las $A$, and $p h z H$, which mediate the production of virulence factors. In fact, up-regulated transcription of autoinducer synthase (lasI and $r h l I$ ) and 
their cognate receptor (lasR and $r h l R$ ) genes may be responsible for the induction of PAO1 biofilm formation and secretion of elastase and pyocyanin because QS genes also mediate virulence factor genes.

\section{Conclusions}

Taken together, this study demonstrated that AI-2 increased $P$. aeruginosa PAO1 biofilm formation, bacterial viability, and virulence production in a dose-dependent manner. Possible mechanisms responsible for the effect of AI-2 may involve the up-regulation of QS systems. Our results support the significance of intercellular signaling in bacterial survival strategies and emerging views on interference with bacterial signaling as a novel means of combating $P$. aeruginosa infections.

\section{Abbreviations}

Al-2: Autoinducer-2; AHL: Acyl homoserine lactones; DPD: 4, 5-dihydroxy-2, 3-pentanedione; ECR: Elastin-Congo red; LB: Luria-Bertani; PBS: Phosphate buffered saline; PI: Propidium iodide; PPB: Pyocyanin production broth; QS: Quorum sensing.

\section{Competing interests}

The authors declare that they have no competing interests.

\section{Authors' contributions}

LHD and YJL conceived and designed the study, LHD performed the study, WZL, FYK and AQ analyzed and interpreted the data, LHD and LXY wrote the manuscript. LHD, LXY and DY revised the manuscript. All authors read and approved the final manuscript.

\section{Availability of data and materials}

Not applicable.

\section{Acknowledgements}

We are grateful to Yu He for his valuable advice to the linguistic revision of the manuscript.

\section{Funding}

This study was supported by the National Natural Science Foundation of China (No.81370744), the fund from Ministry of Education (No.X3387),the Scientific Research Foundation of Chongqing Municipal Health Bureau (Grant No:2013-2-051), the Scientific Research Foundation of The science and Technology Commission of Chongqing (Grant No: cstc2015jcyjA10089) and National Science and Technology Support Project (2012BAI04B05).

\section{Author details}

${ }^{1}$ Department of Neonatology, Children's Hospital, Chongqing Medical University, Chongqing, China. ${ }^{2}$ Ministry of Education Key Laboratory of Child Development and Disorders, Chongqing, China. ${ }^{3}$ Key Laboratory of Pediatrics in Chongqing and Chongqing International Science and Technology Cooperation Center for Child Development and Disorders, Chongqing, China. ${ }^{4}$ Department of Pharmacy, Chongqing Red Cross Hospital, Chongqing, China. ${ }^{5}$ Department of Paediatrics, Children's Hospital of Fudan University, Shanghai, China.

Received: 9 January 2015 Accepted: 23 September 2015 Published online: 29 September 2015

\section{References}

1. Brennan AL, Geddes DM. Cystic fibrosis. Curr Opin Infect Dis. 2002;15(2):175-82.

2. Ciofu O, Fussing V, Bagge N, Koch C, Hoiby N. Characterization of paired mucoid/non-mucoid Pseudomonas aeruginosa isolates from Danish cystic fibrosis patients: antibiotic resistance, beta-lactamase activity and RiboPrinting. J Antimicrob Chemother. 2001;48(3):391-6.
3. Ben Haj Khalifa A, Moissenet D, Vu Thien H, Khedher M. Virulence factors in Pseudomonas aeruginosa: mechanisms and modes of regulation. Ann Biol Clin (Paris). 2011;69(4):393-403.

4. Miller MB, Bassler BL. Quorum sensing in bacteria. Annu Rev Microbiol. 2001;55:165-99.

5. Janjua HA, Segata N, Bernabo P, Tamburini S, Ellen A, Jousson O. Clinical populations of Pseudomonas aeruginosa isolated from acute infections show a wide virulence range partially correlated with population structure and virulence gene expression. Microbiology. 2012;158(Pt 8):2089-98.

6. Herrmann G, Yang L, Wu H, Song Z, Wang H, Hoiby N, et al. Colistin-tobramycin combinations are superior to monotherapy concerning the killing of biofilm Pseudomonas aeruginosa. J Infect Dis. 2010;202(10):1585-92.

7. Bjarnsholt T, Kirketerp-Moller K, Kristiansen S, Phipps R, Nielsen AK, Jensen $P O$, et al. Silver against Pseudomonas aeruginosa biofilms. APMIS. 2007;115(8):921-8.

8. Lemire JA, Harrison JJ, Turner RJ. Antimicrobial activity of metals: mechanisms, molecular targets and applications. Nat Rev Microbiol. 2013;11(6):371-84

9. Hentzer M, Wu H, Andersen JB, Riedel K, Rasmussen TB, Bagge N, et al. Attenuation of Pseudomonas aeruginosa virulence by quorum sensing inhibitors. EMBO J. 2003:22(15):3803-15.

10. Scutera S, Zucca M, Savoia D. Novel approaches for the design and discovery of quorum-sensing inhibitors. Expert Opin Drug Discov. 2014;9(4):353-66.

11. Vendeville A, Winzer K, Heurlier K, Tang CM, Hardie KR. Making 'sense' of metabolism: autoinducer-2, LuxS and pathogenic bacteria. Nat Rev Microbiol. 2005;3(5):383-96

12. Duan K, Dammel C, Stein J, Rabin H, Surette MG. Modulation of Pseudomonas aeruginosa gene expression by host microflora through interspecies communication. Mol Microbiol. 2003;50(5):1477-91.

13. Roy V, Meyer MT, Smith JA, Gamby S, Sintim HO, Ghodssi R, et al. Al-2 analogs and antibiotics: a synergistic approach to reduce bacterial biofilms. Appl Microbiol Biotechnol. 2013;97(6):2627-38.

14. Geier H, Mostowy S, Cangelosi GA, Behr MA, Ford TE. Autoinducer-2 triggers the oxidative stress response in Mycobacterium avium, leading to biofilm formation. Appl Environ Microbiol. 2008;74(6):1798-804.

15. Lu W, Yu J, Ai Q, Liu D, Song C, Li L. Increased constituent ratios of Klebsiella sp., Acinetobacter sp., and Streptococcus sp. and a decrease in microflora diversity may be indicators of ventilator-associated pneumonia: a prospective study in the respiratory tracts of neonates. PLoS ONE. 2014;9(2):e87504.

16. Yang $Y X, X u Z H$, Zhang $Y Q$, Tian J, Weng LX, Wang LH. A new quorumsensing inhibitor attenuates virulence and decreases antibiotic resistance in Pseudomonas aeruginosa. J Microbiol. 2012;50(6):987-93.

17. Sarkar R, Chaudhary SK, Sharma A, Yadav KK, Nema NK, Sekhoacha M, et al Anti-biofilm activity of Marula - a study with the standardized bark extract. J Ethnopharmacol. 2014;154(1):170-5.

18. Kong KF, Jayawardena SR, Indulkar SD, Del Puerto A, Koh CL, Hoiby N, et al. Pseudomonas aeruginosa AmpR is a global transcriptional factor that regulates expression of $\mathrm{AmpC}$ and PoxB beta-lactamases, proteases, quorum sensing, and other virulence factors. Antimicrob Agents Chemother. 2005;49(11):4567-75.

19. Smith $K M, B u Y$, Suga $H$. Induction and inhibition of Pseudomonas aeruginosa quorum sensing by synthetic autoinducer analogs. Chem Biol. 2003;10(1):81-9.

20. Deng C, Li X, Zou Y, Wang J, Wang J, Namba F, et al. Risk factors and pathogen profile of ventilator-associated pneumonia in a neonatal intensive care unit in China. Pediatr Int. 2011;53(3):332-7.

21. Auger S, Krin E, Aymerich S, Gohar M. Autoinducer 2 affects biofilm formation by Bacillus cereus. Appl Environ Microbiol. 2006;72(1):937-41.

22. Bachtiar EW, Bachtiar BM, Jarosz LM, Amir LR, Sunarto H, Ganin H, et al. Al-2 of Aggregatibacter actinomycetemcomitans inhibits Candida albicans biofilm formation. Front Cell Infect Microbiol. 2014;4:94.

23. Azakami H, Teramura I, Matsunaga T, Akimichi H, Noiri Y, Ebisu S, et al. Characterization of autoinducer 2 signal in Eikenella corrodens and its role in biofilm formation. J Biosci Bioeng. 2006;102(2):110-7.

24. Gonzalez Barrios AF, Zuo R, Hashimoto Y, Yang L, Bentley WE, Wood TK. Autoinducer 2 controls biofilm formation in Escherichia coli through a nove motility quorum-sensing regulator (MqsR, B3022). J Bacteriol. 2006;188(1):305-16.

25. Yoshida A, Ansai T, Takehara T, Kuramitsu HK. LuxS-based signaling affects Streptococcus mutans biofilm formation. Appl Environ Microbiol. 2005;71(5):2372-80. 
26. McNab R, Ford SK, El-Sabaeny A, Barbieri B, Cook GS, Lamont RJ. LuxS-based signaling in Streptococcus gordonii: autoinducer 2 controls carbohydrate metabolism and biofilm formation with Porphyromonas gingivalis. J Bacteriol. 2003;185(1):274-84.

27. Wang Y, Yi L, Zhang Z, Fan H, Cheng X, Lu C. Biofilm formation, host-cell adherence, and virulence genes regulation of Streptococcus suis in response to autoinducer-2 signaling. Curr Microbiol. 2014;68(5):575-80.

28. Rickard AH, Palmer Jr RJ, Blehert DS, Campagna SR, Semmelhack MF, Egland $P G$, et al. Autoinducer 2: a concentration-dependent signal for mutualistic bacterial biofilm growth. Mol Microbiol. 2006;60(6):1446-56.

29. Winzer K, Hardie KR, Burgess N, Doherty N, Kirke D, Holden MT, et al. LuxS: its role in central metabolism and the in vitro synthesis of 4-hydroxy-5-methyl3(2H)-furanone. Microbiology. 2002;148(Pt 4):909-22.

30. Doherty N, Holden MT, Qazi SN, Williams P, Winzer K. Functional analysis of luxS in Staphylococcus aureus reveals a role in metabolism but not quorum sensing. J Bacteriol. 2006;188(8):2885-97.

31. Hassett DJ, Cuppoletti J, Trapnell B, Lymar SV, Rowe JJ, Yoon SS, et al. Anaerobic metabolism and quorum sensing by Pseudomonas aeruginosa biofilms in chronically infected cystic fibrosis airways: rethinking antibiotic treatment strategies and drug targets. Adv Drug Deliv Rev. 2002;54(11):1425-43.

\section{Submit your next manuscript to BioMed Central and take full advantage of:}

- Convenient online submission

- Thorough peer review

- No space constraints or color figure charges

- Immediate publication on acceptance

- Inclusion in PubMed, CAS, Scopus and Google Scholar

- Research which is freely available for redistribution 